\title{
RESENHA/REVIEW
}

Jesus de Paula ASSIS ${ }^{1}$

CROSBY, A., W. The Measure of reality - Quantification and Western Society, 1250 - 1600. Cambridge: Cambridge University Press, 1997. 245p.

“A pauta musical foi o primeiro gráfico da Europa", afirma o autor à página 144 de seu “ $A$ Medida da Realidade. Essa é, de fato, a primeira afirmação pretensamente original do livro, já passados quase dois terços da leitura. Antes disso, Crosby segue a via consagrada de apresentar os antecedentes históricos, as condições de momento, uma pincelada metodológica - para tentar deixar claro o que será e o que não será aceito como explicação dos fatos históricos - e reunir tudo isso em um caldeirão do qual deverá sair, senão invencível, pelo menos bem de saúde, a Revolução Científica. Como em um bom romance, vários personagens se encontram, cruzam suas vidas, atuam muitas vezes sem perceber a presença dos outros e todas as ações convergem para o tema principal.

Afirmar que Crosby é realmente bem-sucedido na empreitada é difícil. Depende muito de o que se deva aceitar como método de procura de evidência e, uma vez encontrada a evidência pelo tal método, de como se deva avaliar o achado.

Quando se sai das ciências naturais, nas quais, pelo menos em uma versão um tanto idealizada, sempre se tem à mão um método aceito por todos os participantes, a discussão sobre método quase se confunde com a sobre o assunto. Crosby, vale adiantar, não chafurda no lamaçal da metodologia histórica nem perde de vista uma separação clara entre o discurso sobre o assunto e o assunto a ser discutido. Apesar de uma ou outra

1 Pesquisador do Nupes 
ocorrência da palavra "mentalité", estamos livres de alteridades, pós isso e aquilo, revisitas, releituras, resgates etc.

O argumento principal é que, durante os séculos XIII e XIV (especial atenção é dada ao período 1280-1350, mais ou menos), os pensadores europeus tornavam mais precisos seus hábitos intelectuais. Nesse período, é inventado o relógio mecânico - e, com ele, uma demanda por precisão quanto a horas trabalhadas, horas de descanso etc. -, a notação arábica de posição (não propriamente inventada, mas adotada) - que tornava possível calcular no papel pois, com algarismos romanos, pode-se anotar, mas não operar sem o auxílio de um ábaco -, as especulações de intelectuais como Nicolau de Cusa e Nicolau de Oresme sobre a possibilidade do heliocentrismo, do tempo absoluto, do espaço como um continente independente do conteúdo, e assim por diante.

Todos esses fatores são condições necessárias, mas certamente não suficientes para uma mudança radical de mentalidade, que possa tirar a Europa da Idade Média e lançá-la em uma era de precisão, conquistas materiais e intelectuais sem precedentes. Falta o que Crosby chama "o acender de um fósforo". E esse fósforo foi a visualização. Todas essas adições intelectuais e técnicas aliaram-se a três atividades aparentemente desligadas, mas unidas pela idéia de que é possível ver processos abstratos, dispondo-os sobre o papel. Essas atividades tiveram a ver com o desenvolvimento da polifonia - que exigia uma notação mais precisa do que a usada no canto gregoriano -, da perspectiva - que tornava as figuras representações mais ou menos fiéis das coisas, colocando em segundo plano valores subjetivos como importância dos personagens, santidade das ações representadas etc. - e da contabilidade - que colocava sobre o papel o andamento abstrato da economia, usando para isso tabelas recém-desenvolvidas e numerais arábicos, com algoritmos de operação segundo a posição do numeral (um uso que os intelectuais acadêmicos ainda relutavam em adotar plenamente).

Essas três atividades, todas nascidas da demanda por precisão em vista da crescente complexidade de cada campo respectivo - do canto gregoriano à polifonia, das transações simples às operações a crédito, da representação baseada em idéias pré-concebidas à necessidade de descrever um ambiente tridimensional de forma acessível para qualquer um, independentemente do conhecimento deste sobre a ação descrita - estão mais ligadas ao fazer do que ao teorizar; às atividades mundanas, mais que às acadêmicas.

Assim, chega-se ao quadro completo: fatores antecedentes, fatores precipitantes e alguns fatores secundários (a urbanização entre os séculos XI e XIV, a criação de universidades, a disseminação da leitura em silêncio) lançam a Europa em um novo clima intelectual. 
Uma pausa metodológica. E por que devemos aceitar essa lista como relevante? Resposta do autor (p.5 e 26): apreciando o que é "kitsch", ou seja, popular e impensado, e analisando idéias sem restrição quanto à respeitabilidade intelectual das fontes temos como avaliar a infiltração de uma idéia em uma sociedade. Crosby pergunta "quão amplamente e por quanto tempo a Europa ocidental manteve um certo conceito?" (p.26) e responde que, se for por muito tempo e muito amplamente, então estamos autorizados a afirmar que o conceito é geral. Por exemplo, se encontrarmos exigências de precisão em atividades tão distantes quanto música e pintura e contabilidade, então estaremos autorizados a falar que os europeus estavam de fato preocupados com precisão.

O problema prático evidente com esse tipo de aproximação é que ela é estatística. A partir de que ponto podemos afirmar que um conceito é "amplamente" adotado? Se escolhermos a pintura, em quantas obras ele deverá poder ser discernido para afirmarmos que realmente é um centro de atenção? Em 50\% ou mais das obras, ou em 1\% delas, mas que representariam $90 \%$ das dos principais autores? Ou os autores seriam principais justamente porque suas obras foram influentes? Mudados os termos para hoje, o método poderia levar à conclusão de que o centro de preocupação artístico da música contemporânea não está com Stockhausen ou Ligeti, mas com Madonna e Julio Iglesias. Claro, os conceitos que aparecem nas "obras" dos últimos são muito mais difundidos e influenciam muito mais músicos do que as técnicas e idéias dos dois primeiros. Então, para escapar disso, deveríamos redefinir música (dizendo, no caso, que ela é absolutamente diferente daquilo que a maioria das pessoas julga que ela seja), o que invalidaria nossas pretensões empíricas, já que precisaríamos, nós, os não-agentes absolutamente externos, reclassificar a realidade a fim de que ela fornecesse os dados que corroborariam o modelo.

No fim de contas, se os envolvidos têm suficiente bom senso, o método pára quando a cauda começa a abanar o cão. Mas se é assim, se, no fim da estrada, deve-se apelar para "obras representativas", "autores importantes" etc., por que a maquiagem metodológica? Esse não é um problema restrito a este livro, mas presente em todas as pretensas discussões metodológicas em história (e, também, em uma área aparentemente distante, mas totalmente afim: a crítica literária). A honestidade de "li muito, estudei, acho que sei alguma coisa e vou mostrar a você" é substituída por um fátuo discurso sobre métodos, relevância etc., que será abandonado na próxima esquina sem maior cerimônia.

Assim, Crosby, apesar do apego ao kitsch, termina por atestar a relevância da contabilidade para o desenvolvimento da idéia de que precisão é essencial para o progresso da cultura ocidental não pelo exame de 
centenas de manuais da época, mas pelo exame de um autor e pela menção de que este era um intelectual refinado, em sintonia com as discussões intelectuais de sua época e ligado direta (conhecimento pessoal) ou indiretamente (leitura, correspondência) a intelectuais acadêmicos.

Tudo isso não desmerece o livro. Apenas aponta não propriamente uma falha, mas um traço onipresente no discurso histórico, ainda mais se o assunto for ciência. (Usando o próprio método sobre esse tipo de livro, pode-se dizer que os historiadores estão mais preocupados com precisão do que talvez deveriam, e que traduzem isso mais em retórica do que em ação.) Fim da pausa metodológica.

O ponto central de Crosby é que atividades práticas nas quais intervém precisão foram os germes do pensamento científico ocidental. A idéia aparece aqui e ali na literatura, especialmente quando alguém cita o início de Duas novas ciências, de Galileu Galilei:

A atividade constante que vós venezianos apresentais em vosso famoso arsenal sugere à mente estudiosa um vasto campo para investigação, especialmente aquela parte do trabalho que envolve mecânica; pois nesse mister todo tipo de instrumentos e de máquinas é constantemente construído por muitos artesãos, entre os quais deve haver aqueles que, parte por experiência adquirida, parte por suas próprias observações, tornaram-se altamente capazes e inteligentes para dar explicações. $^{2}$

Ou seja, se se pretende conhecimento preciso do mundo, conhecimento com poder preditivo, deve-se aliar o conhecimento direto (entenda-se, prático) desse mundo à teoria. Mas não conhecimento qualquer, mas conhecimento que vem da experiência repetida e observada com inteligência. E não teoria qualquer, mas teoria enraizada na observação cuidadosa. E esse cuidado só pode ser completamente realizado por quem tem de fazer não para especular, mas para entregar, para responder a demandas práticas e urgentes. Galileu não deixa por menos: escolhe logo um arsenal.

Crosby propõe recuar essa admissão da importância da prática extra-acadêmica no desenvolvimento da ciência moderna em aproximadamente 300 anos. E por que deveríamos segui-lo? Afinal, ao aceitar a polifonia, a perspectiva e a contabilidade como motores dessa pretensão de precisão prática, teremos de admitir que entre elas e Galileu passaram

2 Duas novas ciências, traduzido para o inglês por Henry Crew e Afonso de Salvio. Encyclopaedia Britanica Great Books of the Western World, 1952. 
300 anos de relativa quietude. O que nos devolveria à originalidade de Galileu e ao ponto de partida. Essa questão não vai ser resolvida no âmbito do livro, se é que ela tem como sê-lo em qualquer caso. Pois, afinal, remete ao problema de decidir se, dadas as condições de contorno, os personagens apareceriam de qualquer jeito ou se algum espaço ainda estaria preservado para a originalidade e unicidade das pessoas.

Em todo caso, ao aceitar os argumentos do autor, pelo menos ficamos nas mãos com uma cadeia que liga os esforços intelectuais dos dois Nicolaus medievais ao terceiro, Copérnico, moderno. Este deixa de aparecer no cenário por um fiat e passa a herdeiro de uma tradição intelectual de três séculos. Os gráficos de Descartes deixam de ser uma contribuição quase extraterrena, para se tornarem herdeiros primeiro de Oresme, que os aplicou timidamente ao movimento (p.68) e, mais amplamente, da música medieval que, precisando fugir da simplicidade do canto monofônico, teve de desenvolver uma representação pictórica dos sons, relacionando-os como curvas afinação x tempo. Como a música fazia parte da educação básica, do quadrívio, quem aprendia rudimentos de música já se familiarizava com a idéia de representação precisa e, daí à geometria analítica, o passo, se não é menor - porque não é mesmo -, é, pelo menos, mais compreensível. É evidente que resta a questão do "por que Descartes?", que nos devolve ao ponto de partida. Mas esse tipo de questão sempre será colocável em história e não deve nos incomodar muito.

$\mathrm{O}$ fato é que existe um certo conforto em encontrar continuidades. Agrada ao espírito inquisidor e ao mesmo tempo desconfiado de teorias muito abrangentes e dogmáticas reencontrar o cotidiano nos grandes eventos históricos. Isso torna os heróis dispensáveis e devolve vida às áridas narrativas históricas herdadas do passado, nas quais ou o motor da história eram heróis tão distantes como improváveis ou então era um mecanismo tão impessoal e determinista que a humanidade ficava reduzida ao papel de figurante. Assim, poderíamos preferir como definição de $e x$ plicação histórica algo como:

Explicações históricas raramente são da natureza de uma bola de bilhar atingindo outra, de 'causas' no sentido estrito. São, muito mais freqüentemente, um processo de iluminação gradual do fato a ser explicado, pela reunião de outros em seu redor que, como lâmpadas, parecem colocar mais luz sobre ele. ${ }^{3}$

3 WHITE, L. Medieval Religion and Technology, apud COHEN, 1994, p.517. 
É isso o que Crosby faz, e faz bem. Ganha-se em esclarecimento ao fim das páginas, sem que o autor tenha aderido de maneira dura a algum dogmatismo. Sai-se confortável, pois nenhuma cauda abanou nenhum cão. O que, de certa forma, já é muito quando se percorre a literatura que lida com história das idéias. De fato, o que se quer explicar é um fato único, uma ocorrência isolada neste planeta: só a cristandade ocidental desenvolveu em alto grau uma noção de precisão que resultou nas ciências naturais e formais de que dispomos hoje. Assim, dada a unicidade da ocorrência, existe pouco o que explicar (e, menos ainda, quando o esforço é explicar por que o desenvolvimento não ocorreu em outras sociedades, vide Cohen, 1994) e muito mais a iluminar. Desde que o bom senso prevaleça, o que, no caso de Cohen, significa falar de contabilidade, música e pintura e nada mais, não haverá problema. Mesmo porque, no que diz respeito à contabilidade, a idéia não é nova. Historiadores e sociólogos - especialmente na vertente marxista - sempre gostaram de falar do surgimento da ciência moderna a partir das demandas de um protocapitalismo. Quanto à pintura, toda a mitologia que cerca Leonardo mostra suficientemente que esse item é também muito querido pelos caçadores de raízes do pensamento moderno. Na música, bem, essa é considerada matematizável desde sempre na cultura ocidental e seu aparecimento na lista de precedentes importantes da ciência não deve surpreender ninguém.

Ao final da leitura, pelo que se disse acima, fica evidente que não foram encontradas no texto novas idéias, nem velhas idéias em novos lugares, nem métodos novos, nem velhos métodos aplicados criativamente. Permanece a clareza da exposição, o rigor, e o poder de síntese para encaixar 350 anos de cultura em poucas páginas. E é isso o que se pode fazer, sem medo, hoje. Textos dogmáticos como os de Mumford (1934) - com originais, mas pouco claras divisões entre períodos científico-tecnológicos - ou como os de historiadores excessivamente mecânico-marxistas (na linha "dadas as condições tais e tais, um Galileu ou um Newton tinham de inevitavelmente aparecer") ou ainda a historiografia mais comum dos manuais científicos (a que apresenta a popular sucessão de heróis que fizeram o desenvolvimento das diversas disciplinas científicas) estão irremediavelmente gastos. Pode-se, hoje, apenas “iluminar" despretensiosamente. E, nisso, a lanterna de Crosby é clara, tornando os objetos distintos, mas não clara demais, o que apagaria seus contornos.

\section{Referências bibliográfica}

COHEN, H. F. The scientific revolution: A historiographical inquiry. Chicago: The University of Chicago Press, 1994.

MUNFORD, L. Technics and civilization. New York: Harcourt Brace and Co., 1934. 